\title{
Intratibial injection of patient-derived tumor cells from giant cell tumor of bone elicits osteolytic reaction in nude mouse
}

\author{
LEQIN XU ${ }^{1,2}$, ZHIPENG WU $^{1}$, ZHENHUA ZHOU $^{1}$, XINGHAI YANG $^{1 *}$ and JIANRU XIAO ${ }^{1 *}$ \\ ${ }^{1}$ Department of Orthopedic Oncology, Changzheng Hospital, Second Military Medical University, Shanghai 200003; \\ ${ }^{2}$ Department of Science and Education, Xiamen Hospital of Traditional Chinese Medicine, Fujian \\ University of Traditional Chinese Medicine, Xiamen, Fujian 361001, P.R. China
}

Received February 26, 2016; Accepted July 11, 2017

DOI: $10.3892 / \mathrm{ol} .2018 .9148$

\begin{abstract}
There have been various reports in the literature of an in vivo model for giant cell tumor of bone (GCTB). However, few suitable animal models of GCTB have been established, due to the fact that GCTB contains three histologically different cell types. To the best of our knowledge, injection of patient-derived GCTB cells into bone environment has not been reported until now. In the present study, the biological behavior of GCTB cells in nude mice was investigated through intratibial injection of patient-derived GCTB cells. Patient-derived GCTB cells were obtained from 5 patients who had not undergone chemo- and radiotherapy. Once isolated, the cell suspension was injected into the tibias of nude mice. The growth process was monitored by weekly observation and photographic documentation using X-ray. Four months after injection, nude mice were sacrificed and the injected tibial samples were fixed, and further analyzed using micro-computed tomography (micro-CT), standard histology, tartrate-resistant acid phosphatase (TRAP) staining and mitochondrial immunofluorescence staining. X-ray, micro-CT and standard histology revealed osteolytic destruction in the proximal end of the tibia. TRAP staining identified TRAP-positive, osteoclast-like cells distributed in the bone marrow interface of the lesion area. Anti-human mitochondrial immunofluorescence staining confirmed that the surviving cells in the osteolytic destruction were of human GCTB cell origin. These findings indicate that intratibial injection of patient-derived GCTB cells may elicit osteolytic destruction in nude mice. The
\end{abstract}

Correspondence to: Professor Xinghai Yang or Professor Jianru Xiao, Department of Orthopedic Oncology, Changzheng Hospital, Second Military Medical University, 415 Fengyang Road, Shanghai 200003, P.R. China

E-mail: cnspineyang@163.com

E-mail: jianruxiao83@163.com

*Contributed equally

Key words: giant cell tumor of bone, bone lysis, intratibial injection, animal model, bone environment results of the current study present a novel animal model for GCTB, opening new perspectives to investigate this disease and develop therapeutic agents.

\section{Introduction}

Giant cell tumor of bone (GCTB) is an aggressive osteolytic tumor that typically originates in the epimetaphyseal region of a long bone and frequently occurs in the distal end of the femur or the proximal end of the tibia $(1,2)$. GCTB is clinically defined as a benign bone tumor, but is characterized by locally aggressive growth and usually leads to an extensive bone lesion. Radiographically, the lesion of GCTB is purely lytic, exhibiting geographic bone destruction (3). Although it rarely causes mortality, the recurrence rate for GCTB has been reported as $18-50 \%(4-8)$.

Histologically, GCTB is composed of three major cell types: Multinucleated, osteoclast-like giant cells; monocytic round-shaped, macrophage-like cells; and spindle-shaped, fibroblast-like stromal cells (9-11). The stromal cells are considered to be the neoplastic component of GCTB as they are the only proliferating cell component in long-term cultures $(12,13)$ and express oncogenes (14-16). The macrophage-like cells, which are recruited by stromal cells, are considered to be osteoclast precursors, and are able to fuse into multinucleated osteoclast-like giant cells, with the latter eventually causing aggressive bone resorption and skeletal destruction (17-19). As stable cell lines of the multinucleated giant cells and monocyte-derived macrophages have not been established, individual GCTB cell components cannot be maintained in culture. As such, it has not been possible to determine the efficacy of antitumor agents on GCTB in vitro $(20,21)$.

Although several in vivo GCTB models are available, studies on this tumor are restricted as the development of the in vivo model is incomplete, associated with a short survival time or does not induce osteolytic lesion (22-24). Stromal cells injected subcutaneously into immunocompromised mice do not produce giant cells $(22,24,25)$. Furthermore, tumor tissues grown on chick chorioallantoic membranes do not appear to recruit chicken monocytes to synthesize new giant cells despite increased vascularization from the membrane, and the survival time is typically 10 days (23). Thus, it was speculated that GCTB monocytes do not originate from the 
circulation, but rather arise from the bone marrow. Therefore, it is necessary to directly inject GCTB cells into the bone environment (1).

The intratibial injection method is one of the most widely used murine models to investigate cancer cell growth within the bone environment. It has been used to establish orthotopic models for investigating osteosarcoma biology within the bone environment (26). It has also been used to research bone cancer pain and cancer bone metastasis in prostate (27), and breast cancer $(28,29)$. In addition, the intratibial injection method leads to a reproducible and valuable model for drug testing (27).

Thus far, attempts to grow GCTB in animal models and derive suitable cell lines from primary tumors have failed. This has limited research in the pathobiology of GCTB and the development of specific anti-GCTB agents. In the present report, this problem was addressed by examining whether it was possible to establish an orthotopic model of GCTB in nude mice following intratibial injection of patient-derived tumor cells.

\section{Materials and methods}

Ethics statement and patient samples. The use of all patient-derived tumor specimens was approved by the Institutional Review Board and the Research Ethics Committee of Changzheng Hospital (Shanghai, China). Written informed consent was obtained individually from each patient. The pathological diagnosis of GCTB was confirmed by biopsy prior to surgical excision. Specimens were obtained at the time of surgery from patients undergoing tumor resection, and the diagnosis of GCTB was verified postoperatively by a bone pathologist. Tissue samples from 5 cases ( 2 male: 3 female) of GCTB were used in the present study, and all experiments were performed with three mice per 5 patient sample. The mean age of the five study patients was $24.4 \pm 1.5$ years (median age, 25 years; range, 19-28 years). Patients were underwent pathological examination for pathological diagnosis and patients with GCTB were selected for the present study.

Reagents and established cell lines. The human fetal osteoblast hFOB1.19 cell line was obtained from the Institute of Biochemistry and Cell Biology of Shanghai (Shanghai, China). Dulbecco's modified Eagle's medium-F12 (DMEM-F12), DMEM, penicillin/streptomycin and fetal bovine serum (FBS) were purchased from Thermo Fisher Scientific, Inc. (Gibco; Waltham, MA, USA). Collagenase B was obtained from Roche Diagnostics GmbH (Mannheim, Germany). DAPI and the tartrate-resistant acid phosphatase (TRAP) staining kit was purchased from Merck KGaA (Sigma-Aldrich; Darmstadt, Germany). The primary antibody against human Mitochondria (HuMi) was obtained from EMD Millipore (Chemicon; Billerica, MA, USA).

Patient-derived GCTB cells collection and cells culture. Patient-derived GCTB cells were isolated from tumor samples from tumor resections at the Changzheng Hospital as aforementioned. The tissue was mechanically cut into small pieces, and digested with $1.5 \mathrm{mg} / \mathrm{ml}$ collagenase $\mathrm{B}$ for $3 \mathrm{~h}$ at $37^{\circ} \mathrm{C}$ in DMEM containing $4.5 \mathrm{~g} / 1$ glucose supplemented with $10 \%$
FBS, $100 \mathrm{U} / \mathrm{ml}$ penicillin and $100 \mu \mathrm{g} / \mathrm{ml}$ streptomycin. Cells were collected by filtration $(100-\mu \mathrm{m}$ diameter filter), then centrifuged at $200 \mathrm{x}$ g for $5 \mathrm{~min}$ at room temperature and washed twice in PBS. The cells were counted using a hemocytometer and resuspended at a density of $5 \times 10^{5}$ cells $/ 20 \mu \mathrm{l}$ PBS. For morphological observation and TRAP staining, $1 \times 10^{5}$ cells were seeded in 6-well plate and cultured in DMEM supplemented with $10 \% \mathrm{FBS}, 100 \mathrm{U} / \mathrm{ml}$ penicillin and $100 \mu \mathrm{g} / \mathrm{ml}$ streptomycin in a $37^{\circ} \mathrm{C}$ humidified incubator with $5 \% \mathrm{CO}_{2}(30)$.

The hFOB1.19 cells were maintained in DMEM-F12 supplemented with $10 \% \mathrm{FBS}, 100 \mathrm{U} / \mathrm{ml}$ penicillin and $100 \mu \mathrm{g} / \mathrm{ml}$ streptomycin in a humidified atmosphere with $5 \% \mathrm{CO}_{2}$ at $34^{\circ} \mathrm{C}$. The medium was replenished every 2-3 days. After reaching 70-80\% confluence, cells were passaged by treatment with $0.25 \%$ trypsin. Prior to intratibial injection, the cells were detached from the petri dish with $0.25 \%$ trypsin and centrifuged at $200 \times \mathrm{g}$ for $5 \mathrm{~min}$ at room temperature. Cells were resuspended into a $5 \times 10^{5}$ cell/20 $\mu 1$ cell suspension in PBS.

Morphological observations. Cells $\left(2 \times 10^{5}\right.$ cells/well) were incubated for $48 \mathrm{~h}$ in 24 -well plates. Following incubation, the medium was removed and the cells were washed once with PBS. Morphology was observed using a phase contrast inverted microscope (Leica Microsystems $\mathrm{GmbH}$, Wetzlar, Germany). For detection of osteoclasts, cells $\left(2 \times 10^{5}\right.$ cells/well $)$ were incubated for $48 \mathrm{~h}$ in 24 -well plates. Following incubation, the medium was removed and cells were washed twice with PBS. Cultures were fixed for $10 \mathrm{~min}$ at room temperature with $4 \%$ paraformaldehyde in PBS and then washed four times with PBS. Fixed cells were stained for TRAP using the Acid Phosphatase Leukocyte (TRAP) kit, according to the manufacturer's protocol (cat. no. 387A-1KT; Sigma-Aldrich; Merck $\mathrm{KGaA}$ ). Staining was observed using a phase contrast inverted microscope at a x400 magnification (Olympus Corporation, Tokyo, Japan).

Experimental animals. A total of fifteen male 4-5-week-old BALB/c nu/nu mice (weighing 18-20 g) were purchased from Shanghai SLAC Laboratory Animal Co., Ltd. (Shanghai, China). The animals were housed in the specific pathogen-free animal facilities with free access to food and water. The temperature was maintained at $20-26^{\circ} \mathrm{C}$ and a relative humidity of $40-70 \%$. Lighting conditions, $12 \mathrm{~h}$ a day fluorescent light and $12 \mathrm{~h}$ of darkness.

Intratibial injection of patient-derived GCTB cells. Patient-derived GCTB cells and hFOB1.19 cells were resuspended in PBS at a working concentration of $5 \times 10^{5}$ cells $/ 20 \mu 1$. Patient-derived GCTB cells were prepared from the fresh giant cell tumor of bone specimens without any culture. The intratibial bone injection was performed in 4- to 5-week-old BALB/c, $\mathrm{nu} / \mathrm{nu}$ mice anesthetized with pentobarbital $(50 \mathrm{mg} / \mathrm{kg})$ via a percutaneous approach (27). Briefly, the proximal end of the left tibia was exposed surgically, the knee was maintained in a flexed position, and $20 \mu \mathrm{l}$ of PBS-containing patient-derived GCTB cells were injected into the bone marrow space with a 26-gauge needle. Control mice were injected with hFOB1.19 cells or PBS in the same manner. Four months after injection, nude mice were sacrificed and the injected tibial 
samples were fixed, and further analyzed as described below. Procedures involving animals and their care were conducted in conformity with the National Institutes of Health guidelines (31), and were approved by the Animal Care and Use Committee of the Second Military Medical University.

Detection of bone lesions by radiography. Animals were anesthetized and radiographs were obtained using a Kodak DXS 4000 Pro system (Kodak, Rochester, NY, USA) for 1 min at $35 \mathrm{kV}$ on day 0 , and weekly following intratibial injection. The radiographs were analyzed for the presence and type of bony lesion (osteolytic, osteoblastic or mixed lytic/blastic).

Three-dimensional, micro-computed tomography (micro-CT). Micro-CT was performed using a SkyScan 1076 Desktop X-ray microtomographer (Bruker microCT, Kontich, Belgium). The excised mouse legs were secured in polystyrene imaging tubes and scanned [x50 magnification; $5.86 \mu \mathrm{m}$ resolution; $7.5 \mathrm{sec}$ exposure time (40 kV and 258UA); 0.45 rotation step; $180^{\circ}$; and a $1 \mathrm{~mm}$ Aluminum filter]. Image reconstruction was performed with volumetric reconstruction software (version 2.4.0.0) and 3D image analysis was performed with CT Analyzer software (version 1.8.1.2) and 3DVisualization software (version 2.0.0.4) (all from Bruker microCT).

The bone volume (trabecular bone volume/tissue volume, $\mathrm{BV} / \mathrm{TV}$ ), and the bone lesion area (bone lesion/normal bone, $\mathrm{BL} / \mathrm{NB}$ ) were determined by three-dimensional structural parameters analysis.

Histological analysis of bone destruction. Following X-ray analysis, the tibial specimens were processed by fixation with $4 \%$ paraformaldehyde in PBS for $24 \mathrm{~h}$ at $4^{\circ} \mathrm{C}$, followed by decalcification in 0.5 M EDTA. Paraffin-embedded sections were cut with a microtome into $4-\mu \mathrm{m}$ thick sections, then stained with hematoxylin and eosin (H\&E) for histological examination of tumor growth, and general form of the tibia. For H\&E staining, tissue slices underwent standard rehydration and deparaffinization procedures (32) and were then stained with hematoxylin for $10 \mathrm{~min}$ and eosin for $3 \mathrm{~min}$ at room temperature. The H\&E stained sections were imaged using the Leica DM 4000B microscope at x400 magnification (Leica Microsystems GmbH).

Detection of TRAP activity. Unstained tibia sections were deparaffinized and rehydrated for detection of TRAP activity as an osteoclast marker. Briefly, specimens were equilibrated for $20 \mathrm{~min}$ at room temperature in $0.2 \mathrm{M}$ sodium acetate buffer containing $50 \mathrm{mM} \mathrm{L-(+)-tartaric} \mathrm{acid} \mathrm{in} \mathrm{deionized} \mathrm{water,}$ $\mathrm{pH}$ 5.0. The sections were incubated in the TRAP staining reagent for $1 \mathrm{~h}$ at $37^{\circ} \mathrm{C}$ and then at room temperature for 20-30 min until the color reaction was complete. The sections were air-dried and mounted with Eukitt medium. TRAP stained sections were analyzed using the Olympus DP71 phase contrast inverted microscope at x400 magnification (Olympus Corporation).

Cell tracking using anti-HuMi immunofluorescence. Unstained tibia sections were deparaffinized, rehydrated and processed for human specific antigens (mouse anti-human mitochondria; cat. no. MAB 1273; HuMi, 1:50; Chemicon, Temecula, CA,
USA) to determine the presence of human cells. Sections were incubated overnight at $4{ }^{\circ} \mathrm{C}$ with the aforementioned primary antibodies diluted in PBS containing $10 \%$ normal goat serum. The following day, sections were treated with the appropriate secondary antibodies (goat anti-mouse IgG; cat no. ab150113; 1:1,000; Abcam, Cambridge, MA, USA) for $1 \mathrm{~h}$ at room temperature. Negative controls involved the same procedures with the omission of the primary antibody. DAPI was used for counterstaining nuclei for $5 \mathrm{~min}$ at room temperature. The immunostained sections were analyzed using the Olympus BX60 and IX71 epiflourescence microscopes with Olympus DP-70 digital acquisition system at x400 magnification (Olympus Corporation). Images were obtained using 40X objectives and processed with Adobe Photoshop CS3 version 10.0.1 software (Adobe Systems, Inc., San Jose, CA, USA).

Statistical analysis. All of the quantitative experiments were performed more than three times. A Student's t-test was used to determine significant differences between various groups. $\mathrm{P} \leq 0.05$ was considered to indicate a statistically significant difference. All statistical analysis was carried out using SPSS version 18.0 (SPSS, Inc., Chicago, IL, USA).

\section{Results}

Clinical characteristics and cellular analysis. The clinical characteristics of the 5 patients included in the present study are presented in Table I. The H\&E and TRAP staining of patient tumor tissues are presented in Fig. 1 (Fig. 1A-E and F-J, respectively). Patient-derived GCTB cells were isolated from patient samples using the collagenase B digestion method. They contained the three major cell types, namely mesenchymal stromal cells, round monocytes of macrophage lineage, and multinucleated giant cells (Fig. 1K-O). The multinucleated giant cells were positively stained with TRAP to confirm this characteristic osteoclast feature (Fig. 1P-T). The components, morphology and characteristics of patient-derived GCTB cells were consistent with the clinical pathology reports and H\&E staining.

$X$-ray and micro-CT analysis of bone lesions. The sites of intratibial injections in mice were visible on weekly X-rays. Radiographic data revealed the appearance of osteolytic bone lesions 2 months following intratibial injection of patient-derived GCTB cells (Fig. 2). The intensity of osteolysis gradually increased as time passed (Fig. 2A). Notably, the $\mathrm{BL} / \mathrm{NB}$ was significantly increased in GCTB mice (Fig. 2C). In control mice that received injections with hFOB1.19 or PBS, there was no evidence of bone damage in the proximal end of the tibia (Fig. 2A and C).

Micro-CT analysis confirmed marked osteolytic destruction in GCTB mice (Fig. 2B). The analysis revealed that GCTB tumors had almost completely destroyed the tibial bone architecture 4 months after the introduction of primary tumor cells, whereas the tibial bone architecture was intact in PBS alone or hFOB1.19 control mice. The ratio of BV/TV was significantly reduced in GCTB mice compared with the control group (Fig. 2D).

Histological analysis and TRAP staining. Paraffin histology revealed a cavity within the tibias of mice injected with primary 
Table I. Epidemiological and pathological characteristics of 5 patients with GCTB.

\begin{tabular}{lcllll}
\hline Case & Age (years) & Gender & Site & Grade & Remarks \\
\hline GCTB-1 & 26 & Female & Tibia & I & Primary \\
GCTB-2 & 19 & Male & Radial & II & Primary \\
GCTB-3 & 24 & Male & Tibia & III & Primary \\
GCTB-4 & 28 & Female & Femur & I & Primary \\
GCTB-5 & 25 & Female & Sacrum & II & Primary \\
\hline
\end{tabular}

GCTB, giant cell tumor of bone.

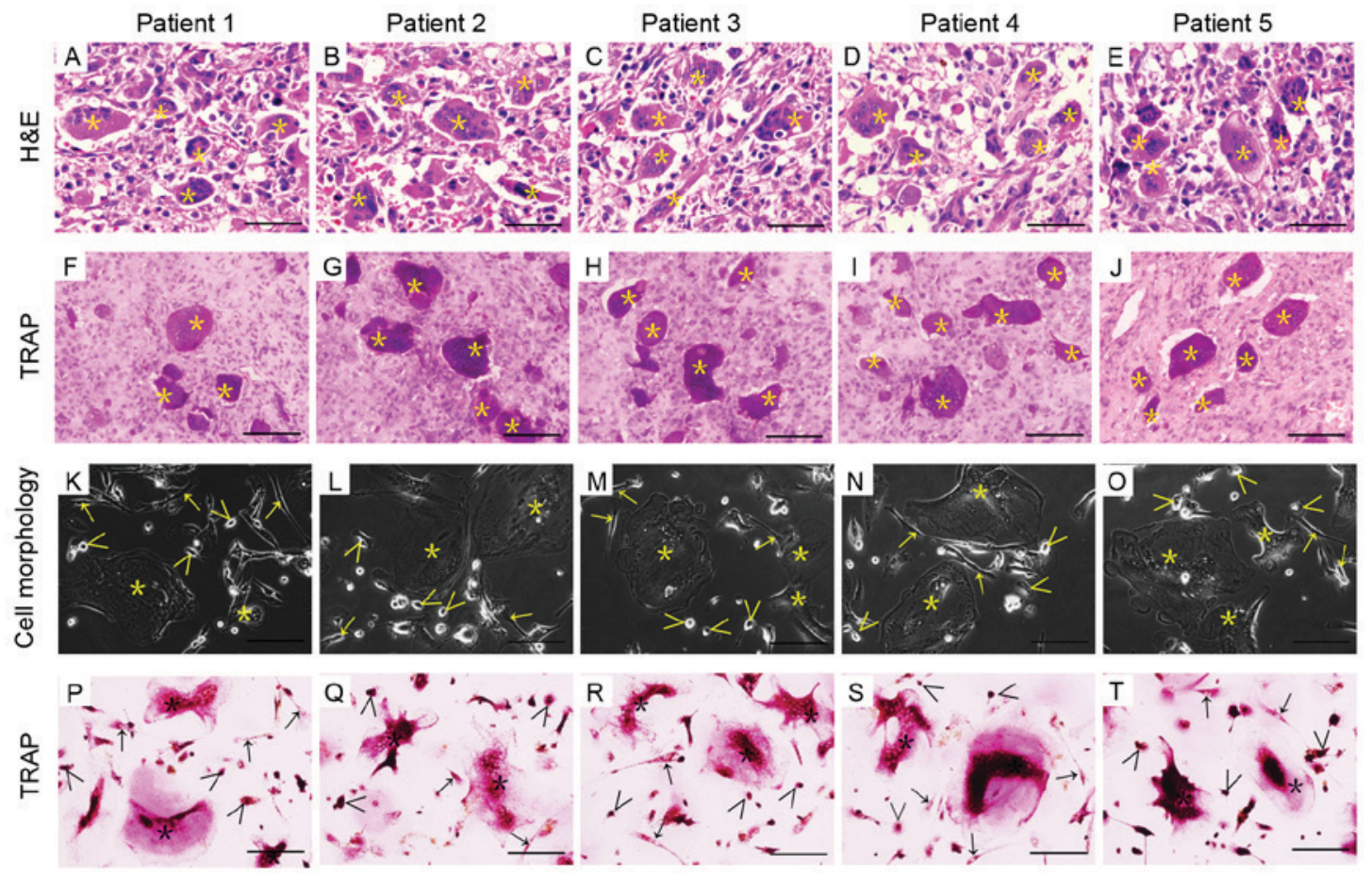

Figure 1. Histological features of GCTB tissues and their corresponding cell morphology. (A-E) H\&E staining of patient tumor tissues with GCTB. (F-J) TRAP-enzyme staining of GCTB tissues. (K-O) Phase-contrast photomicrographs of primary GCTB cells isolated from fresh tumor samples taken from different patients. (P-T) TRAP-enzyme staining revealed TRAP-positive multinucleated osteoclasts in GCTB cells from different patients. Giant cells are marked with asterisks $\left({ }^{\star}\right)$, monocytes with greater-than signs $(>)$, and stromal cells with arrows $(\rightarrow)$. Bars represent $50 \mu \mathrm{m}$. H\&E, hematoxylin and eosin; TRAP, tartrate-resistant acid phosphatase; GCTB, giant cell tumor of bone.

GCTB cells. The visible cavities were surrounded with tumor cells arranged in a barrier around the opening (Fig. 3A). Multinucleated TRAP-positive cells, which are osteoclast-like cells, were clearly visible within the bone matrix (Fig. 3B and C).

GCTB cells survival at the lesion site. Four months after transplantation, human GCTB cells were detected with an antibody against HuMi at the bone lesion site, indicating the presence of transplanted cells amongst a background of unstained mouse cells (Fig. 3D-F).

\section{Discussion}

The recent development of in vitro culture of human GCTB cells has contributed to the understanding of the phenotypes and physiology of GCTB. Although the stromal cell subcutaneous injection model and chick chorioallantoic membrane model have been utilized $(22,23,25)$, little is known regarding the orthotopic behavior of human GCTB cells due to the difficulties in establishing a stable cell line that allows for detailed investigation of their biology. In the present study, patient-derived tumor cells isolated from GCTB were injected into the bone marrow of nude mice in order to establish an orthotopic murine model for human GCTB, a method proven to aid engraftment and develop bone lesions in the murine bone marrow microenvironment. Successful engraftment of GCTB-originating cells and subsequent bone lesions were observed in bone environment of mice.

In the current study, histological analysis of GCTB xenograft tissue sections were performed using anti-HuMi, $\mathrm{H} \& \mathrm{E}$ and TRAP staining. Histological analysis of $\mathrm{H} \& \mathrm{E}$ and TRAP staining revealed that the patient-derived GCTB cells survived, and caused an osteolytic reaction in the bone environment. Furthermore, previous studies have reported that 


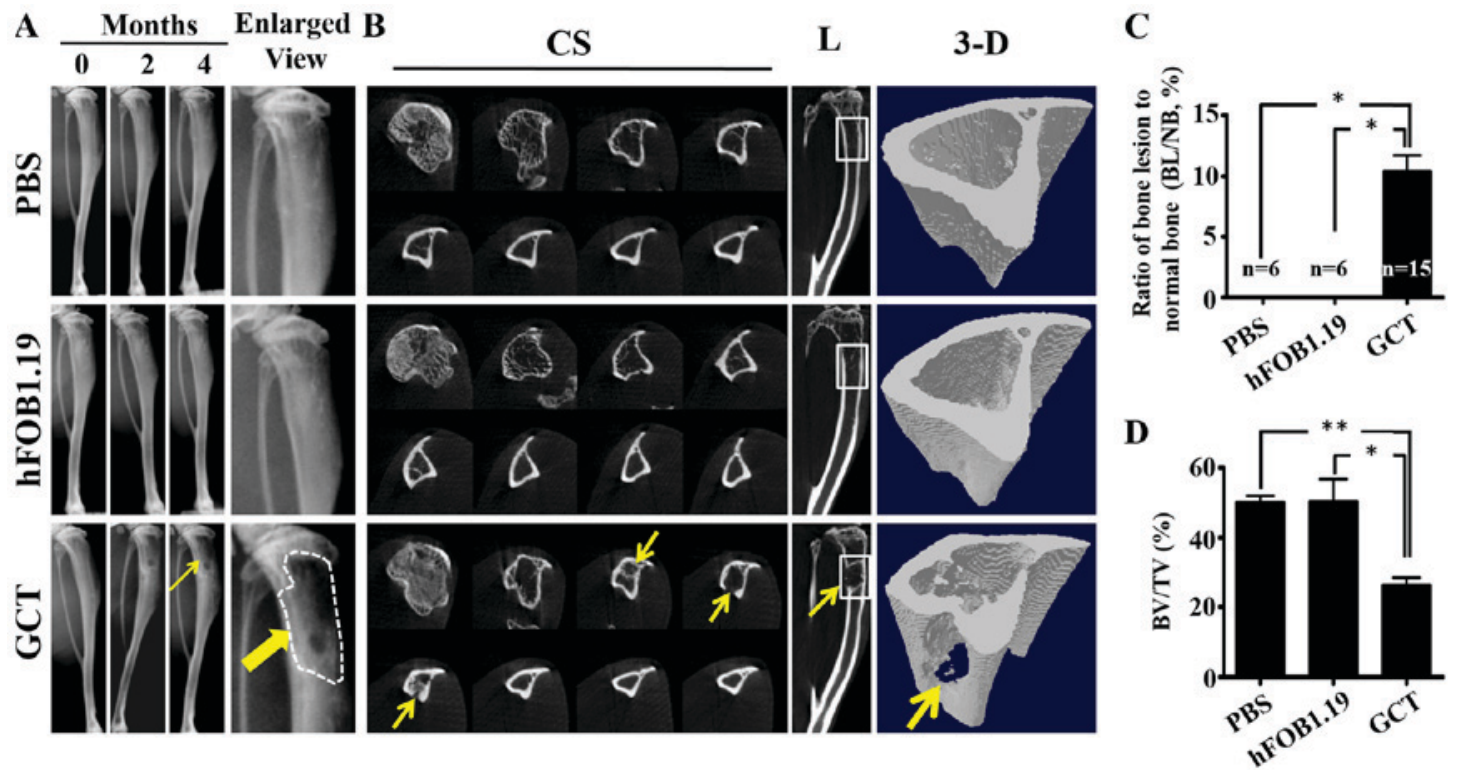

Figure 2. Digital radiography and micro-CT image of osteolytic destruction in the tibias of nude mice. (A) Mice received intratibial injections of PBS alone or $5 \times 10^{5} \mathrm{hFOB} 1.19$ cells or GCTB primary cells. Extensive bone lysis was observed in mice injected with patient-derived GCTB cells $(\rightarrow)$. (B) Serial 2D cross-sectional and longitudinal micro-CT images of PBS-, hFOB1.19- or GCTB-injected tibiae acquired at $20 \mu \mathrm{m}$ resolution. Osteolytic destruction $(\rightarrow)$ was observed in cross-sectional and longitudinal micro-CT sections following primary GCTB cell injection. Representative 3-D reconstruction of micro-CT images of the tibiae from each treatment group, revealing osteolytic lesions in the proximal tibia of mice that received GCTB-injection. (C) BL/NB was significantly increased in GCTB-injection mice. "P<0.05. (D) BV/TV of bone lesions was calculated using a CT analyzer. The percentage of BV/TV was significantly reduced in GCTB-injected mice. ${ }^{*} \mathrm{P}<0.05 ;{ }^{* *} \mathrm{P}<0.01$. Micro-CT, micro-computed tomography; GCTB, giant cell tumor of bone; BL/NB, bone lesion/normal bone ratio; BV/TV, bone volume/tissue volume ratio; CS, cross-sectional; L, longitudinal.
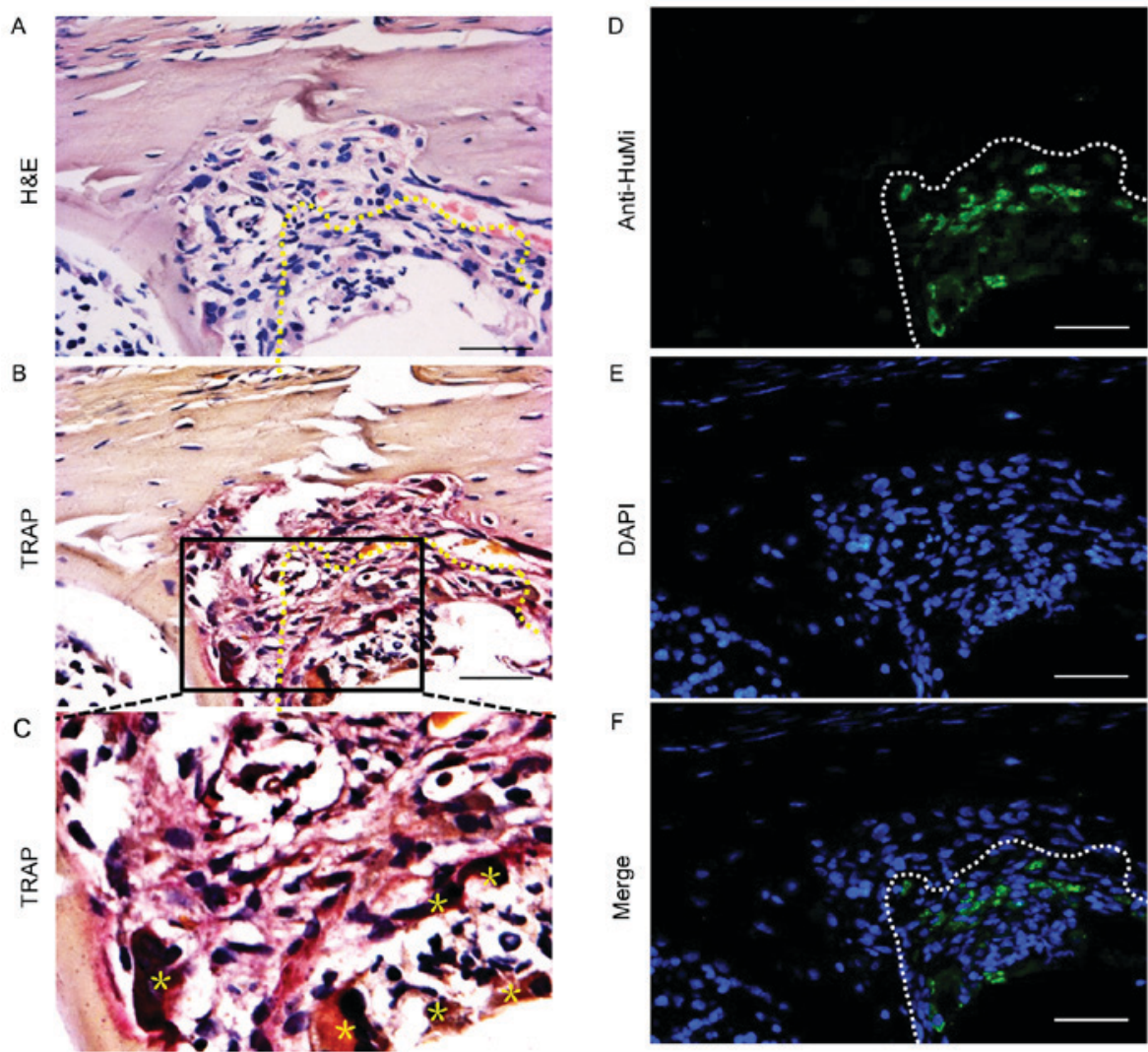

Figure 3. Immunofluorescence microphotographs revealing the pattern of human cell markers at the bone lesion site. Tissue sections (4- $\mu \mathrm{m}$ thick) were taken from the tibial bone 120 days after injection with patient-derived GCTB cells. (A) H\&E stained demonstrated that animals injected with patient-derived GCTB cells exhibited osteolytic destruction at the proximal tibia. (B) TRAP-positive osteoclasts were observed at the bone lesions in mice injected with patient-derived GCTB cells. (C) Osteoclasts $\left(^{\star}\right)$ were distributed within the trabecular bone marrow interface and the bone matrix. (D) Anti-HuMi (green) staining revealed the presence of transplanted cells amongst a background of non-staining mouse cells. (E) Cell nuclei were visualized with DAPI staining (blue). The overlay of human mitochondria fluorescence and DAPI staining are presented as merged images (F). Bars represent $50 \mu \mathrm{m}$. H\&E, hematoxylin and eosin; TRAP, tartrate-resistant acid phosphatase; GCTB, giant cell tumor of bone; HuMi, human mitochondria. 
stromal cells can differentiate into mature osteoblasts, adipocytes and chondrocytes (11,12,33-36). Observed differences between the results of the present study and others may indicate that stromal cells undergo multidirectional differentiation, which may be influenced by the tissue microenvironment. As such, different environmental conditions may produce varied differentiation features and functions.

The X-ray and micro-CT features of bone destruction in the present model were similar to the clinical imaging characteristics, revealing pure lytic lesions without any degree of matrix calcification or ossification and surrounding reactive sclerosis (3). However, biopsies of nude mice tibia did not exhibit the same clinicopathological features as the chick chorioallantoic membrane model, which is characterized by the presence of numerous multinucleated giant cells that are uniformly distributed amongst mononuclear spindle-like stromal cells and other monocytes (19). In the present study, a large number of TRAP-positive cells were identified surrounded the surviving stromal cells, and were distributed at the surface of the tibia trabecular and matrix bone. As reported in the literature, stromal cells are capable of secreting a variety of cytokines, including stromal cell-derived factor-1 (37), macrophage colony-stimulating factor (38) and monocyte chemotactic protein-1 (39). The release of these cytokines results in the recruitment of monocytes and further secretion of interleukin (IL)-6 (40), matrix metalloproteinases $(41,42)$, and parathyroid hormone-related protein (43) to promote osteoclast fusion and bone resorption.

A limitation of the current study was the use of patient-derived GCTB cells containing all types of cells from GCTB tissue. Isolation of the different subtypes of GCTB primary cells using flow cytometry to compare the survival and tumorigenicity of different cell populations within the bone environment was not performed. Therefore, additional studies are required to evaluate the survival and tumorigenicity of the various cell types or combinations. Previously, it has been reported that GCTB stromal cells transfected with green fluorescence protein survived 52 weeks in vivo (24). However, isolation of stromal cells from GCTB in vitro results in the rapid loss of expression of receptor activator of nuclear factor- $\mathrm{\kappa B}$ ligand (44). This suggests that the pathogenesis of GCTB requires cellular interactions, which provide a suitable microenvironment for tumor growth.

In conclusion, the present study described the establishment of a novel xenograft model of GCTB using patient-derived tumor cells. This murine xenograft GCTB model produced visible osteolytic damage in the proximal tibias of nude mice. Anti-HuMi immunofluorescence staining confirmed that the surviving cells in the osteolytic destruction were of human GCTB cell origin. These findings may contribute to the understanding of the pathogenesis of GCTB, and thus aid in the improvement of diagnosis, treatment and patient outcome.

\section{Acknowledgements}

Not applicable.

\section{Funding}

The present study was supported by the Science and Technology Planning Projects of Xiamen Science \& Technology
Bureau, China (grant no. 3502Z20164039) and the Science and Technology Commission of Shanghai Municipality (grant no. 09411950500 and 12R21418300).

\section{Availability of data and materials}

All data generated or analyzed during this study are included in this published article.

\section{Authors' contributions}

LX conducted the experiment studies. ZW and ZZ performed the statistical analysis and drafted the manuscript. JX and XY made substantial contributions to conception and design of this work and critically revised the manuscript. All authors read and approved the final manuscript.

\section{Ethics approval and consent to participate}

The use of all patient-derived tumor specimens was approved by the Institutional Review Board and the research ethics committee of Shanghai Changzheng Hospital (approval no. 2011/081), which appeared in the proceedings of the meeting of the Ethics Committee on November 18, 2011.

\section{Patient consent to participate}

Written informed consent was obtained individually from each patient.

\section{Competing interests}

The authors declare that they have no competing interests.

\section{References}

1. Cowan RW and Singh G: Giant cell tumor of bone: A basic science perspective. Bone 52: 238-246, 2013.

2. Alsulaimani SA and Turcotte RE; Canadian Orthopaedic Oncology Society (CANOOS) collaborators: Iterative curettage is associated with local control in giant cell tumors involving the distal tibia. Clin Orthop Relat Res 471: 2668-2674, 2013.

3. Stacy GS, Peabody TD and Dixon LB: Mimics on radiography of giant cell tumor of bone. AJR Am J Roentgenol 181: 1583-1589, 2003

4. Prosser GH, Baloch KG, Tillman RM, Carter SR and Grimer RJ: Does curettage without adjuvant therapy provide low recurrence rates in giant-cell tumors of bone? Clin Orthop Relat Res 435: 211-218, 2005.

5. Kremen TJ Jr, Bernthal NM, Eckardt MA and Eckardt JJ: Giant cell tumor of bone: Are we stratifying results appropriately? Clin Orthop Relat Res 470: 677-683, 2012.

6. Lin WH, Lan TY, Chen CY, Wu K and Yang RS: Similar local control between phenol- and ethanol-treated giant cell tumors of bone. Clin Orthop Relat Res 469: 3200-3208, 2011.

7. Klenke FM, Wenger DE, Inwards CY, Rose PS and Sim FH: Recurrent giant cell tumor of long bones: Analysis of surgical management. Clin Orthop Relat Res 469: 1181-1187, 2011.

8. Klenke FM, Wenger DE, Inwards CY, Rose PS and Sim FH: Giant cell tumor of bone: Risk factors for recurrence. Clin Orthop Relat Res 469: 591-599, 2011.

9. Goldring SR, Schiller AL, Mankin HJ, Dayer JM and Krane SM: Characterization of cells from human giant cell tumors of bone. Clin Orthop Relat Res: 59-75, 1986.

10. Komiya S, Sasaguri Y, Inoue A, Nakashima M, Yamamoto S, Yanagida I and Morimatsu M: Characterization of cells cultured from human giant-cell tumors of bone. Phenotypic relationship to the monocyte-macrophage and osteoclast. Clin Orthop Relat Res 258: 304-309, 1990. 
11. Salerno M, Avnet S, Alberghini M, Giunti A and Baldini N: Histogenetic characterization of giant cell tumor of bone. Clin Orthop Relat Res 466: 2081-2091, 2008.

12. Wülling M, Delling G and Kaiser E: The origin of the neoplastic stromal cell in giant cell tumor of bone. Hum Pathol 34: 983-993, 2003.

13. Lau CP, Ng PK, Li MS, Tsui SK, Huang L and Kumta SM: p63 regulates cell proliferation and cell cycle progressionassociated genes in stromal cells of giant cell tumor of the bone. Int J Oncol 42: 437-443, 2013.

14. Wuelling M, Delling G and Kaiser E: Differential gene expression in stromal cells of human giant cell tumor of bone. Virchows Arch 445: 621-630, 2004.

15. Babeto E, Conceição AL, Valsechi MC, Peitl Junior P, de Campos Zuccari DA, de Lima LG, Bonilha JL, de Freitas Calmon M, Cordeiro JA and Rahal P: Differentially expressed genes in giant cell tumor of bone. Virchows Arch 458: 467-476, 2011.

16. Chen S, Li C, Wu B, Zhang C, Liu C, Lin X, Wu X, Sun L, Liu C, Chen B, et al: Identification of differentially expressed genes and their subpathways in recurrent versus primary bone giant cell tumors. Int J Oncol 45: 1133-1142, 2014.

17. Fujikawa Y, Quinn JM, Sabokbar A, McGee JO and Athanasou NA: The human osteoclast precursor circulates in the monocyte fraction. Endocrinology 137: 4058-4060, 1996.

18. Massey HM and Flanagan AM: Human osteoclasts derive from CD14-positive monocytes. Br J Haematol 106: 167-170, 1999.

19. Lau YS, Sabokbar A, Gibbons CL, Giele H and Athanasou N: Phenotypic and molecular studies of giant-cell tumors of bone and soft tissue. Hum Pathol 36: 945-954, 2005.

20. Haque AU and Moatasim A: Giant cell tumor of bone: A neoplasm or a reactive condition? Int J Clin Exp Pathol 1: 489-501, 2008.

21. Werner M: Giant cell tumour of bone: Morphological, biological and histogenetical aspects. Int Orthop 30: 484-489, 2006.

22. James IE, Dodds RA, Olivera DL, Nuttall ME and Gowen M: Human osteoclastoma-derived stromal cells: Correlation of the ability to form mineralized nodules in vitro with formation of bone in vivo. J Bone Miner Res 11: 1453-1460, 1996.

23. Balke M, Neumann A, Szuhai K, Agelopoulos K, August C, Gosheger G, Hogendoorn PC, Athanasou N, Buerger $\mathrm{H}$ and Hagedorn M: A short-term in vivo model for giant cell tumor of bone. BMC Cancer 11: 241, 2011.

24. Singh S, Singh M, Mak I and Ghert M: Expressional analysis of GFP-tagged cells in an in vivo mouse model of giant cell tumor of bone. Open Orthop J 7: 109-113, 2013.

25. Oreffo RO, Marshall GJ, Kirchen M, Garcia C, Gallwitz WE, Chavez J, Mundy GR and Bonewald LF: Characterization of a cell line derived from a human giant cell tumor that stimulates osteoclastic bone resorption. Clin Orthop Relat Res 229-241, 1993.

26. Long F, Cai X, Luo W, Chen L and Li K: Role of aldolase A in osteosarcoma progression and metastasis: In vitro and in vivo evidence. Oncol Rep 32: 2031-2037, 2014.

27. Park SI, Kim SJ, McCauley LK and Gallick GE: Pre-clinical mouse models of human prostate cancer and their utility in drug discovery. Curr Protoc Pharmacol Chapter 14: Unit 14.15, 2010 .

28. Hoff BA, Chughtai K, Jeon YH, Kozloff K, Galbán S, Rehemtulla A, Ross BD and Galbán CJ: Multimodality imaging of tumor and bone response in a mouse model of bony metastasis. Transl Oncol 5: 415-421, 2012.

29. Futakuchi M and Singh RK: Animal model for mammary tumor growth in the bone microenvironment. Breast Cancer (Tokyo, Japan) 20: 195-203, 2013.
30. Balla P, Moskovszky L, Sapi Z, Forsyth R, Knowles H, Athanasou NA, Szendroi M, Kopper L, Rajnai H, Pinter F, et al: Epidermal growth factor receptor signalling contributes to osteoblastic stromal cell proliferation, osteoclastogenesis and disease progression in giant cell tumour of bone. Histopathology 59: 376-389, 2011.

31. National Research Council (US) Committee for the Update of the Guide for the Care and Use of Laboratory Animals: Guide for the Care and Use of Laboratory Animals. 8th edition. National Academies Press, Washington, DC, 2011.

32. Tang X, Jin R, Qu G, Wang X, Li Z, Yuan Z, Zhao C, Siwko S, Shi T, Wang P, et al: GPR116, an adhesion G-protein-coupled receptor, promotes breast cancer metastasis via the Gaq-p63RhoGEF-Rho GTPase pathway. Cancer Res 73: 6206-6218, 2013.

33. Huang L, Teng XY, Cheng YY, Lee KM and Kumta SM: Expression of preosteoblast markers and Cbfa-1 and Osterix gene transcripts in stromal tumour cells of giant cell tumour of bone. Bone 34: 393-401, 2004.

34. Murata A, Fujita T, Kawahara N, Tsuchiya H and Tomita K: Osteoblast lineage properties in giant cell tumors of bone. J Orthop Sci 10: 581-588, 2005.

35. Ghert M, Simunovic N, Cowan RW, Colterjohn N and Singh G: Properties of the stromal cell in giant cell tumor of bone. Clin Orthop Relat Res 459: 8-13, 2007.

36. Yang T, Zheng XF, Li M, Lin X and Yin QS: Stimulation of osteogenic differentiation in stromal cells of giant cell tumour of bone by zoledronic acid. Asian Pac J Cancer Prev 14: 5379-5383, 2013.

37. McQuibban GA, Butler GS, Gong JH, Bendall L, Power C, Clark-Lewis I and Overall CM: Matrix metalloproteinase activity inactivates the CXC chemokine stromal cell-derived factor-1. J Biol Chem 276: 43503-43508, 2001.

38. Atkins GJ, Haynes DR, Graves SE, Evdokiou A, Hay S, Bouralexis S and Findlay DM: Expression of osteoclast differentiation signals by stromal elements of giant cell tumors. J Bone Miner Res 15: 640-649, 2000.

39. McQuibban GA, Gong JH, Wong JP, Wallace JL, Clark-Lewis I and Overall CM: Matrix metalloproteinase processing of monocyte chemoattractant proteins generates CC chemokine receptor antagonists with anti-inflammatory properties in vivo. Blood 100: 1160-1167, 2002.

40. Ohsaki Y, Takahashi S, Scarcez T, Demulder A, Nishihara T, Williams R and Roodman GD: Evidence for an autocrine/paracrine role for interleukin-6 in bone resorption by giant cells from giant cell tumors of bone. Endocrinology 131: 2229-2234, 1992.

41. Sasaguri Y, Komiya S, Sugama K, Suzuki K, Inoue A, Morimatsu M and Nagase H: Production of matrix metalloproteinases 2 and 3 (stromelysin) by stromal cells of giant cell tumor of bone. Am J Pathol 141: 611-621, 1992.

42. Ueda Y, Imai K, Tsuchiya H, Fujimoto N, Nakanishi I, Katsuda S, Seiki M and Okada Y: Matrix metalloproteinase 9 (gelatinase B) is expressed in multinucleated giant cells of human giant cell tumor of bone and is associated with vascular invasion. Am J Pathol 148: 611-622, 1996.

43. Cowan RW, Singh G and Ghert M: PTHrP increases RANKL expression by stromal cells from giant cell tumor of bone. J Orthop Res 30: 877-884, 2012.

44. Morgan T, Atkins GJ, Trivett MK, Johnson SA, Kansara M, Schlicht SL, Slavin JL, Simmons P, Dickinson I, Powell G, et al: Molecular profiling of giant cell tumor of bone and the osteoclastic localization of ligand for receptor activator of nuclear factor kappaB. Am J Pathol 167: 117-128, 2005. 